Research Article

\title{
Wound healing suppressant effect of vincristine reversed by vitamin A: an experimental study
}

\author{
Venkatadri T.V., Afzal Khan A. K.*
}

Department of Pharmacology, MVJ Medical College and Research Hospital, Hoskote, Bangalore- 562114, India

Received: 24 March 2016

Accepted: 27 April 2016

*Correspondence to:

Dr Afzal Khan A.K.,

Email: drafzalkhan4u

@gmail.com

Copyright: (C) the author(s), publisher and licensee Medip Academy. This is an openaccess article distributed under the terms of the Creative Commons Attribution NonCommercial License, which permits unrestricted noncommercial use, distribution, and reproduction in any medium, provided the original work is properly cited.

\begin{abstract}
Background: Use of antineoplastic drugs pre and postoperatively have shown to adversely affect the healing of surgical wounds. Vincristine is an antineoplastic drug with a wide range of antitumor activity. Prior studies have demonstrated that vincristine impairs skin wound healing.

Methods: In this study we investigated the effect of vitamin A on vincristine induced suppression of healing in two wound models, viz: incision and dead space in rats. Hydroxyproline (measure of collagen) was estimated colorimetrically and breaking strength of the wound and granulation tissue was measured.

Results: Vincristine $\left(60 \mathrm{mcg} / \mathrm{Kg}\right.$ intraperitoneally, on the $3^{\text {rd }}$ wounding day) significantly reduced breaking strength in both incision and dead space wound models. Vitamin A (5000 I.U, Subcutaneously on alternate days) by itself did not alter any of the parameters studied but reversed the suppressant effects of vincristine on wound healing.

Conclusions: Vitamin A by itself produced little effect on healing except a modest increase in granulation mass. But it significantly reversed the healing suppressant effects of vincristine.
\end{abstract}

Keywords: Wound healing, Vincristine, Vitamin A, Antineoplastic agents

\section{INTRODUCTION}

Chemotherapy administered alone or in conjunction with radiation and surgery, is a fundamental mode of cancer treatment. ${ }^{1}$ Surgical operation and chemotherapy are concurrently used in the treatment of various cases of cancer. One of the disadvantages of such a concomitant treatment is retardation of healing time of the surgical wound. ${ }^{2}$

Most chemotherapeutic drugs act by inhibiting cellular metabolism, rapid cell division, and angiogenesis thereby inhibiting many of the pathways that are crucial to appropriate wound healing. Chemotherapeutic drugs may also delay cell migration into the wound, decrease early wound matrix formation, lower collagen production, impair proliferation of fibroblasts, and inhibit contraction of wounds. Current treatment protocols consist of several classes of chemotherapeutic drugs and each class has its own characteristic effects on cancer cells and wound healing. ${ }^{3}$

Plant alkaloids such as vincristine and vinblastine, derived from the periwinkle plant Vinca rosea have a wide range of antitumor activity. They affect cell replication by de-polymerizing microtubule assemblies, effectively halting cell division during metaphase. Prior animal studies in mice have demonstrated that vincristine impairs skin wound healing by causing a transient decrease in wound tensile strength on postoperative day 3 , which resolves by postoperative days 7 and 21 . $^{1}$

Vitamin A has been shown to promote wound healing by increasing fibroblast differentiation, collagen synthesis, wound strength and by decreasing infection. ${ }^{4}$ 
It has also been reported to possess antineoplastic activity. ${ }^{5,6}$ It has been claimed to attenuate/abolish healing suppressant actions of antineoplastic agents like radiation and chemotherapy without suppressing their antineoplastic activity. ${ }^{7,8}$ Vitamin A supplements have been commonly used to inhibit the catabolic effects of corticosteroids on wound healing. ${ }^{4}$

The present study was undertaken in order to study the effect of Vitamin A on wound healing in rats treated with vincristine

\section{METHODS}

Singly housed male albino rats (150-250 g) were used in this study. Permission was taken from the institutional animal ethics committee to conduct the study. Following an overnight fasting, the animals were anaesthetized with pentobarbitone, $3 \mathrm{mg} / 100$ grams body weight (Apetho and resea rch chemicals, Mumbai) and suitably wounded after shaving the area to be operated to bear either incision or dead space wounds. The wounds were not dressed and no systemic or local antimicrobial agent was used. Animals suspected to carry infection were excluded from the study. Animals were weighed at the beginning and every alternate day. Animals bearing a given wound were divided into four groups, each group containing eight animals. First group of animals received vincristine (Tamil Nadu Dadha Pharmaceuticals Ltd) $60 \mathrm{mcg} / \mathrm{Kg}$, Intraperitoneally, on the $3^{\text {rd }}$ day after wounding. Second group of animals received only vitamin A ( U.S. VitaminIndia Ltd) 5000 I.U, S.C on alternate days for 10 days, a third group received both vincristine and vitamin $\mathrm{A}$, while the fourth group (control) animals received only saline.

Incision wounds were made by the method of Ehrlich and Hunt. ${ }^{9}$ Sutures were removed on $7^{\text {th }}$ day. The breaking strength of each wound was measured by continuous and constant water flow technique on the $10^{\text {th }}$ day. ${ }^{10}$

Dead space wounds were created by implanting a polypropylene tube $(2.5 \times 0.5 \mathrm{~cm})$ beneath the dorsal paravertebral lumbar skin. On day ten the harvested granulation tissue was subjected to physical as well as biochemical evaluation. Hydroxyproline (measure of collagen) was estimated colorimetrically and breaking strength of the granulation tissue was measured by continuous water flow technique. ${ }^{11,10}$

\section{RESULTS}

\section{Incision wound}

As shown in Table 1, the breaking strength of 10 day old incision wounds was significantly reduced $(p<0.001)$ by vincristine. Vitamin A supplementation significantly ( $p<0.001$ ) reversed the effect of vincristine, but vitamin A by itself did not alter breaking strength significantly.

\section{Dead space wounds}

Table 1 shows the effects of vincristine, vitamin A and vincristine+vitamin A on dead space wounds. The breaking strength of granulation tissue was significantly ( $p<0.01$ ) reduced by vincristine. Vitamin A by itself did not modify breaking but reversed significantly $(p<0.01)$ the suppressant effect of vincristine.

Similarly the hydroxyproline (OHP) content was significantly $(\mathrm{p}<0.001)$ reduced by vincristine. Vitamin A alone did not alter the OHP content but reversed the suppressant effect of vincristine on OHP which was statistically significant $(\mathrm{p}<0.05)$.

The deleterious effects of VNC such as decrease in the body weight and white cell count were also found to be significantly ( $p<0.001$ ) ameliorated in animals with concomitant administration of vitamin A.

Table 1: Effects of vincristine, vitamin $A$ and vincristine+vitamin A on wound healing.

\begin{tabular}{|llll|}
\hline $\begin{array}{l}\text { Wound } \\
\text { model }\end{array}$ & $\begin{array}{l}\text { Incision } \\
\text { wound }\end{array}$ & \multicolumn{2}{l|}{ Dead space wound } \\
\hline $\begin{array}{l}\text { Parameters } \\
\text { studied }\end{array}$ & $\begin{array}{l}\text { Breaking } \\
\text { strength }(\mathrm{g})\end{array}$ & $\begin{array}{l}\text { Breaking } \\
\text { strength }(\mathrm{g})\end{array}$ & $\begin{array}{l}\text { Hydroxyprolin } \\
\text { content }(\mathrm{mcg})\end{array}$ \\
\hline Control & $307 \pm 14$ & $308 \pm 26$ & $1803 \pm 95$ \\
\hline Vincristine & $232 \pm 12 * * *$ & $180 \pm 27 * *$ & $1149 \pm 56 * * *$ \\
\hline Vitamin A & $286 \pm 19$ & $270 \pm 30$ & $1758 \pm 59$ \\
\hline $\begin{array}{l}\text { Vincristine } \\
+ \text { Vit. A }\end{array}$ & $301 \pm 06 * * *$ & $264 \pm 06 * *$ & $1325 \pm 37 *$ \\
\hline
\end{tabular}

$($ Mean \pm S.E) $(\mathrm{n}=8, * \mathrm{P}<0.05, * * \mathrm{P}<0.01, * * * \mathrm{P}<0.001)$

\section{DISCUSSION}

The wound healing process consists of highly integrated and overlapping phases such as rapid hemostasis, appropriate inflammation, mesenchymal cell differentiation, proliferation and migration to the wound site, suitable angiogenesis, prompt re-epithelialization and proper synthesis, cross-linking, and alignment of collagen to provide strength to the healing tissue. ${ }^{3}$

Multimodal approach is the basis of the present day therapeutic management of malignancy. Suitable combination of surgery, radiotherapy and chemotherapeutic regimen has proved to be quite efficacious but radiation and cancer chemotherapeutic agents have been reported to suppress the wound healing process. When used perisurgically either of them could lead to wound complications.

Vitamin A has been shown to promote healing that may be normally progressing or the one suppressed by drugs like cyclophosphamide and by radiation without suppressing their antineoplastic activity. ${ }^{7,8,12}$ Vitamin A supplements have also been commonly used to inhibit the catabolic effects of corticosteroids on wound healing. ${ }^{4}$ 
In the present study, vincristine was found to suppress healing in both the incision and dead space wound models. It was found to reduce the weight of the granuloma and there was a reduction in the hydroxyproline content. Hence vincristine may act by suppressing the fibroplasia phase (reduced fibroblasts) as well as collagenation phase (reduced hydroxyproline /granulation tissue). Reduction both in fibroblast mass and collagen can by itself account for reduced breaking strength of both skin wound and harvested granulation tissue.

Vitamin A by itself produced little effect on healing except a modest increase in granulation mass. But it significantly reversed the healing suppressant effects of vincristine.

Vitamin A may benefit the wound by enhancing the early inflammatory phase, including increasing the number of monocytes and macrophages at the wound site, increased fibroblast proliferation, modulation of cellular differentiation and proliferation, increased collagen and hyaluronate synthesis, and decreased MMP (matrix metalloproteases) mediated extracellular matrix degradation. In addition to these vitamin A has also shown to possess anti-oxidant activity. ${ }^{13,3}$

In the present study vitamin A was also found to ameliorate the leucopenia, anemia and loss of body weight induced by vincristine.

Hence it can be concluded that vitamin A reverses the wound healing suppressant effect and other adverse effects of vincristine even though by itself it has little effect on healing.

Funding: No funding sources

Conflict of interest: None declared

Ethical approval: The study was approved by the Institutional Ethics Committee

\section{REFERENCES}

1. Payne WG, Naidu DK, Wheeler CK, Barkoe D, Mentis M, Emerick R. Wound healing in patients with cancer. E Plasty. 2008; 8(9):68-90.

2. Alagol H, Dinc S, Basgut B, Abacioglu N. Temporal variation in the recovery from impairment in adriamycin-induced wound healing in rats. J Circadian Rhythms. 2007;5:6.

3. Guo S, DiPietro LA. Factors affecting wound healing. J Dent Res. 2010;89(3):219-29.

4. Watters CA, Tredget EE. Nutrition and wound healing. The Canadian J CME. 2002:65-74.

5. Goodman de WS. Vitamin A and retinoids in health and disease. N Eng J Med. 1984;310:1023.

6. Bellag W. Vitamin A and retinoids from nutrition to pharmacotherapy in dermatology and oncology. Lancet. 1983;1:860-3.

7. Raju SS, Kulkarni DR. Vitamin A reverse the wound healing suppressant effect of cyclophosphamide. Ind J Pharmac. 1986;18:154-7.

8. Stratford F, Seifter E, Rettura G, Babyatsky M, Levenson SM. Impaired wound healing due to cyclophosphamide alleviated by supplemental vitamin A. Surg Forum. 1980;31:224-5.

9. Ehrlich HP, Hunt TK. The effects of cortisone and anabolic steroids on the tensile strength of healing wounds. Ann Surg. 1969;170:203-6.

10. Lee KH. Studies on mechanism of action of salicylates II. Retardation of wound healing by aspirin. J Pharm Sci. 1968;57:1042-3.

11. Neuman RE, Logan MA. The determination of hydroxyproline. J Biol Chem. 1950;184:299-306.

12. Levenson SM, Gruber CA, Rettura G, Gruber DK, Detrione AA, Seifter E. Supplemental vitamin A prevents acute radiation induced defect in wound healing. Ann Surg. 1984; 200(4):494-512.

13. Mac KJD, Miller LA. Nutritional support for wound healing. Alternative Medicine Review. 2003;8(4):359-77.

Cite this article as: Venkatadri TV, Afzal AKK. Wound healing suppressant effect of vincristine reversed by vitamin A: an experimental study. Int J Basic Clin Pharmacol 2016;5:962-4. 